GRASAS Y ACEITES 70 (2)

April-June 2019, e306

ISSN-L: 0017-3495

https://doi.org/10.3989/gya.0708182

\title{
Shelf-life of traditionally-seasoned Aloreña de Málaga table olives based on package appearance and fruit characteristics
}

\author{
V. Romero-Gil ${ }^{\mathrm{a}, \mathrm{b}}$, F. Rodríguez-Gómez ${ }^{\mathrm{a}}$, M.Á. Ruiz-Bellido ${ }^{\mathrm{b}}$, A. Benítez Cabello ${ }^{\mathrm{a}}$, \\ A. Garrido-Fernández and F.N. Arroyo-López ${ }^{\mathrm{a}, \boldsymbol{}}$ \\ ${ }^{a}$ Food Biotechnology Department. Instituto de la Grasa (IG-CSIC). University Campus Pablo de Olavide, Building 46. Ctra. \\ Utrera, Km 1. 41013 Seville (Spain). \\ ${ }^{b}$ Regulatory Council of PDO Aloreña de Málaga table olives. C/ Caña s/n, 29560, Cerralba, Pizarra, Málaga (Spain). \\ Corresponding author: fnoe@ig.csic.es
}

Submitted: 16 July 2018; Accepted: 18 October 2018. 18 February 2019

SUMMARY: Few studies have been carried out to determine the shelf-life of the Aloreña de Málaga table olive packaging from a physicochemical, microbiological and sensorial point of view. This study showed that under the current packaging conditions, commercial products were free from Enterobacteriaceae, the initial yeast population was progressively inhibited, and only lactic acid bacteria grew during shelf-life. Among the physicochemical characteristics, $\mathrm{pH}$ decreased, lactic acid was formed while citric acid and mannitol were consumed. These changes resulted in gradual olive texture degradation and green color fading during packaging. A multivariate analysis showed that the packaged olives with storage time between 6 and 42 days enjoyed the highest acceptance; while after the $74^{\text {th }}$ day, they were progressively losing acceptability, which was mainly evident at the $131^{\text {st }}$ day of packaging (willingness-to-buy attribute was reduced to $50 \%$ ). A complete microbiological stabilization would require the use of alternative preservatives since thermal treatment is not convenient for this type of olive speciality.

KEYWORDS: Aloreña de Málaga; Evaluation; Lactic acid bacteria; Packaging evolution; Sensory table olives

RESUMEN: Vida de mercado de aceitunas tradicionales Aloreña de Málaga aliñadas basado en la apariencia del envase y características del fruto. Pocos estudios han sido llevados a cabo para determinar la vida de mercado de aceitunas de mesa Aloreña de Málaga envasadas desde un punto de vista físico-químico, microbiológico y sensorial. Este trabajo muestra, cómo, bajo las actuales condiciones de envasado, los productos comerciales están libres de enterobacterias, la población inicial de levaduras se inhibe progresivamente, mientras que las bacterias ácido lácticas son las únicas que se desarrollan durante el envasado. Entre las características físicoquímicas, el pH descendió, se formó ácido láctico mientras que el manitol y el ácido cítrico fueron consumidos. Estos cambios dieron lugar a una progresiva degradación de la textura y a una depreciación del color verde de los frutos. El análisis multivariante realizado mostró que los envasados entre los 6 y 42 días de vida de mercado fueron los mejores valorados por los panelistas, mientras que después de los 74 días, el producto envasado fue perdiendo aceptabilidad, lo cual fue especialmente evidente tras 131 días de envasado (la predisposición de compra fue solo del 50\%). Una completa estabilización microbiológica del producto requeriría del uso de conservantes alternativos, ya que el tratamiento térmico no es muy conveniente para este tipo de elaboración.

PALABRAS CLAVE: Aceitunas de mesa; Aloreña de Málaga; Bacterias ácido lácticas; Evaluación sensorial; Evolución envasados

ORCID ID: Romero-Gil V https://orcid.org/0000-0002-9644-1745, Rodríguez-Gómez F https://orcid.org/00000002-4738-4764, Ruiz-Bellido MA https://orcid.org/0000-0002-8674-8006, Benítez Cabello A https://orcid.org/00000001-9978-1617, Garrido-Fernández A https://orcid.org/0000-0001-8045-5838, Arroyo-López FN https://orcid. org/0000-0001-6308-7746

Citation/Cómo citar este artículo: Romero-Gil V, Rodríguez-Gómez F, Ruiz-Bellido MA, Benítez Cabello A, GarridoFernández A, Arroyo-López FN. 2019. Shelf-life of traditionally- seasoned Aloreña de Málaga table olives based on package appearance and fruit characteristics. Grasas Aceites 70 (2), e306. https://doi.org/10.3989/gya.0708182

Copyright: (C2019 CSIC. This is an open-access article distributed under the terms of the Creative Commons Attribution 4.0 International (CC BY 4.0) License. 


\section{INTRODUCTION}

Aloreña de Málaga processing is a good example of the use of olive fruits for human consumption. In fact, its elaboration presents a great similarity to the procedures described by Columela in his book "De Re Rustica" (Columela, 42). The product may be included in the "Trade Standard Applying to Table Olives" issued by the International Olive Council (IOC, 2004), within the "Trade preparations" section, under the epigraph "Specialities". Such sub-section includes olives different from the usual industrial presentations and, therefore, it characterizes a specific region, usually with a relatively low production. Aloreña de Málaga olives are cracked before brining and their natural initial green color is preserved as much as possible. The product received the first Protected Designation of Origin (PDO) in Spain for olives. Presentations of fruits packaged fresh, stored in cold rooms (fresh green), or fermented in brine for at least 20 days (traditional) are the most appreciated, albeit cured olives (fermented for at least 90 days) are also recognized in the PDO regulation. The definitions of the different presentations, as well as their characteristics and conditions that the products may fulfil are established in the legal documents (DOUE, 2012). They are valid for their usual expected shelf life and distribution area, close to the production region (Guadalhorce Valley, Málaga, Spain). As the recognition of the product quality increases and the areas of commercialization are expanding, a more extended shelf-life is required.

An initial study of the instability of the fresh and traditionally-packaged "seasoned" Aloreña de Málaga olives showed that their short shelf-life $(<7$ days for the fresh green designation) was caused by the activity of microorganisms present in the packaging brine, which increased after washing and the incorporation of seasoning material (Arroyo-López et al., 2009). In fact, after packaging, there was a considerable amount of lactic acid bacteria (LAB) and yeasts in the product. Despite the addition of a preservative (sodium sorbate), they usually grew and caused diverse changes in the physicochemical characteristics (titratable acidity increased while $\mathrm{pH}$ decreased) which, eventually, lead to swelling spoilage; although the product changes (due to low $\mathrm{pH}$ and high titratable acidity) did not present a health risk. As a result, major emphasis was placed on the inhibition of yeasts. However, an excess of the LAB may also lead to certain cases of spoilage like the peculiar alteration in traditional Aloreña de Málaga olives, characterized by the production of whitish and soft regions on the olive surface, which coincided with the maximum population of these microbial groups (Romero-Gil et al., 2016). The dominant species found in the affected packages was a specific genotype of Lactobacillus pentosus; while the microbiota in the non-affected ones was composed of diverse microbial species such as Lactobacillus plantarum, among the bacteria, and Candida tropicalis, Candida parapsilosis, and Lodderomyces elongisporus, among the yeasts.

Hence, the product changes under the current industrial packaging conditions require a revision to provide the basis for further extension of its shelf-life, which is still the primary obstacle for increasing the production of this table olive speciality. Commercial shelf-life is provided by industries on package labelling, and depending on the type of Aloreña de Málaga presentation, ranges from 7 days (in the case of the fresh green presentation) to 1 year (in the case of cured olives). Thus, the aim of this work was a survey of the microbiological and physicochemical changes that traditionallyseasoned Aloreña de Málaga table olives undergo during shelf-life under commercial packaging conditions. The study aims to identify the weaknesses and develop new strategies to improve the final quality of the product and its shelf-life. The work also includes an initial, tentative study of the sensory profile and consumer preferences during the shelf-life of the product.

\section{MATERIALS AND METHODS}

\subsection{Commercial packaging}

This work was carried out with commercial seasoned packaged cracked olives of the Aloreña de Málaga cultivar prepared with fruits previously stored in brine for 20 days (the traditional style, according to the PDO). The packaging from two different industries (denominated as COP and TOL) were used to evaluate the effect of the factory and olive processing history (different conditions prevailing in the storage/fermentation phase). The packaging brine had the following concentrations of chemicals (provided by the industries): 55 $\mathrm{g} / \mathrm{L} \mathrm{NaCl}, 3 \mathrm{~g} / \mathrm{L}$ citric acid, $2 \mathrm{~g} / \mathrm{L}$ potassium sorbate, $1 \mathrm{~g} / \mathrm{L}$ sodium benzoate, $1 \mathrm{~g} / \mathrm{L}$ ascorbic acid, and $0.8 \mathrm{~g} / \mathrm{L}$ lactic acid, expressed as weight/volume. Pet packages (1.6 L total volume) were filled in the industry with $900 \mathrm{~g}$ of olives, $16 \mathrm{~g}$ of seasoning material (a mixture of garlic dices, pepper strips, and small pieces of fennel, and thyme) and $0.7 \mathrm{~L}$ of the abovementioned cover brine. The use of preservatives in this product is necessary since pasteurization may affect the natural flavoring of the aromatic herbs used for seasoning, giving them an unpleasant taste. Nevertheless, some industries pasteurize the cured presentations since the natural-fresh flavor is not essential for them. In this case, the olives suffer important transformations during the previous storage in brine since they follow a lactic fermentation and their surface color turns to brownish. In our case, packages were not pasteurized, moved to the laboratory and maintained at room temperature 
$\left(23 \pm 2{ }^{\circ} \mathrm{C}\right)$. At pre-selected time intervals $(0,6,20$, 42,74 , and 131 days) two containers were removed and used for sensory, microbiological and physicochemical analyses. The determinations of the microbiological and physicochemical characteristics of the packaged olives were extended to 259 days.

\subsection{Physicochemical analysis}

The analyses of $\mathrm{pH}$, titratable acidity, combined acidity, and $\mathrm{NaCl}$ in the cover brine of the packages were performed using the routine methods described by Garrido-Fernández et al., (1997). Individual sugars (glucose, fructose, sucrose and mannitol), organic acids (acetic, lactic, and citric) and ethanol were determined by HPLC according to the methods developed by Sánchez et al., (2000).

Firmness was measured objectively using a Kramer shear compression cell coupled to an Instron Universal Testing Machine (Canton, MA). The cross-head speed was $200 \mathrm{~mm} / \mathrm{min}$. The firmness of the olives was expressed as the mean of 10 measurements, each of which was performed on two cracked, pitted fruits. Shear compression force was expressed as kN/100 g pitted olives.

Surface color analyses were performed on olives using a BYK-Gardner Model 9000 Color-view spectrophotometer, provided with an illuminant $\mathrm{C}$ at $10^{\circ}$ and equipped with computer software to calculate the CIE coordinates: $L^{*}$ (lightness), $a^{*}$ (negative values indicate green while positive values are related to red tones), and $b^{*}$ (negative values indicate blue and positive values associated with yellowish). Interference by stray light was minimized by covering samples with a box, which had a matt black interior. The value for each measurement was the mean of 10 olives.

\subsection{Microbiological analyses}

Brine samples and their decimal dilutions were plated onto the specific selective media described below using a Spiral System model dwScientific (Don Whitley Scientific Limited, England). Subsequently, the plates were counted using a Flash \& Go (IUL, Barcelona, Spain) image analysis system, and the results were expressed as $\log _{10} \mathrm{CFU} /$ $\mathrm{mL}$. Enterobacteriaceae were counted on VRBD (Crystal-violet Neutral-Red bile glucose)-agar (Merck, Darmstadt, Germany), LAB on MRS (de Man, Rogosa and Sharpe)-agar (Oxoid, Basingstoke, UK) with $0.2 \mathrm{~g} / \mathrm{L}$ sodium azide (Sigma, St. Luis, USA), yeasts on YM (yeast-malt-peptone-glucose medium)-agar (Difco ${ }^{\mathrm{TM}}$, Becton and Dickinson Company, Sparks, MD, USA) supplemented with oxytetracycline and gentamicin sulphate as selective agents for yeasts, and finally total aerobic mesophilic microorganisms (AM) on Plate-Count-Agar (PCA, Oxoid). The plates were incubated at $30^{\circ} \mathrm{C}$ for 24 (Enterobacteriaceae and AM) or 48 (LAB and yeasts) hours. The four microbial groups were also studied in fruits. In this case, two olives were pitted, weighed (approximately $10 \mathrm{~g}$ ) and placed in $25 \mathrm{~mL}$ of sterile saline solution $(9 \mathrm{~g} / \mathrm{L} \mathrm{NaCl})$ for homogenization during $2 \mathrm{~min}$ in a stomacher model Seward 400 (Seward Medical Ltd, West Sussex, England). Then, the resulting suspension or appropriate dilutions were spread onto the selective media described above. Counts were expressed as $\log _{10} \mathrm{CFU} / \mathrm{g}$.

\subsection{Evaluation of packages and fruits}

For the sensory analysis, there was agreement between the experts from the industry and Instituto de la Grasa (IG-CSIC) that neither the evaluation sheet of the International Olive Council (IOC, 2011) nor the one developed by Galan-Soldevilla et al., (2013) for Aloreña de Málaga olives, which contains an excessively large number of attributes and was intended for being used by a specifically trained panel, were appropriate for the objectives of this research. Then, as a first task, a simple and easily interpretable evaluation sheet which could be properly used in the consumer tests was developed. It was prepared considering all the previous works but also the special commercialization characteristics of these products (packages and olives) and consisted of two different sections. The first included the attributes that could be appreciated on the packages (swelling and brine leakage) or observed without opening them (color of brines and turbidity); it ended with a global scoring of the package appearance and a question on the overall package acceptability, whose answers were restricted to only two options: yes or no. A second part included specific descriptors related to Aloreña de Málaga fruits (browning, appreciation of external damages, and any kind of defects) and the attributes considered by the sheet IOC (2011) for the green Spanish-style olive classification (acidic, salty, bitter, hardness, crunchiness); it also ended with a global evaluation of the olive quality and acceptability. As in the case of packages, there were only two possible answers: yes (the olives characteristics were good enough to be purchased); or no (they were of poor quality).

The consumer panel was chosen among the personal staff of Instituto de la Grasa-CSIC and was composed of 35 members (16 men and 19 women), selected because of their experience with the sensory evaluation in general and their habitual consumption of table olives. The number of participants is above the minimum number accepted for consumer tests (30 consumers) and represents a still manageable group when used successively throughout the shelf-life, as required in this study. The alternative method of testing samples with different shelf-life periods simultaneously was discarded because of the possibility that the necessary cold storage would not 
guarantee appropriate stabilization. Before the tests, the panellists were informed on the aim of the study, the sensory peculiarities of traditional Aloreña de Málaga olives, and several informal tests were performed to accustom them to the product. The samples were presented in blue glasses, according to the recommendations of the standard COI/T.20/Doc. No 5 (Glass for oil tasting) (IOC, 1987), always coded with three digits, also randomly chosen, and in random order concerning their origins. Only two samples were analyzed in each session. After the first sample test, the panellists were requested to cleanse their palate with tap water before proceeding to the second one. All the descriptors were evaluated on an unstructured scale which ranged from 1 to 11 , in which 1was associatedwith the complete absence of the attribute and 11 with its presence in the highest intensity, and the panellists were asked to mark the intensity of each attribute perceived. The sheets were read by the panel leader with $0.1 \mathrm{~cm}$ precision, except for buying predisposition based on package appearance or olive quality, whose answers (yes or no) were coded as 1 or 0 .

\subsection{Statistical analysis}

Microbiological and physicochemical data were plot using Sigmaplot v. 13 (Systat Software, Inc. Germany). A comparison between the sensory data from the two packaging industries over time was made using the sensory module of XLSTAT (Addinsoft, 2017) by a nested (time within origin) ANOVA. Significant models were those that provided better estimation than just the means at $p<0.05$. The significance of the individual explanatory variables was also tested at $p$ $<0.05$. The estimation of shelf-life according to the acceptation or not of samples by consumers (based on the appearance of packages or quality of fruits) was made by the parametric survival models usually applied to the estimation of the time at which an event occurs based on a Weibull distribution. Then, the time at which quartile $25 \%$, median $50 \%$, and quartile $75 \%$ were estimated based on the model. Sensory scores were also subjected to Principal Components Analysis (PCA) to relate attributes among themselves and with treatments over time. All the statistical analyses were performed using XLSTAT v. 2017 (Addinsoft, Paris, France).

\section{RESULTS}

\subsection{Changes in the microbial populations during shelf-life}

The Enterobacteriaceae were never detected in any package, but AM was always present during shelf-life in both brine and fruits, and their populations showed an erratic evolution (Figures 1 and 2, panel A). The LAB population was absent for around 25 days and then grew sharply to reach population levels between 4 and $6 \log _{10} \mathrm{CFU} / \mathrm{mL}$. In general, their average counts in packages from the TOL industry were lower (but not significantly different) than in the COP industry. The trends in brine and fruits were similar (Figures 1 and 2, panel B). The initial counts of yeasts (3-4 $\left.\log _{10}\right)$ decreased progressively during the first days of shelf-life (Figures 1 and 2, panel C). Overall, their
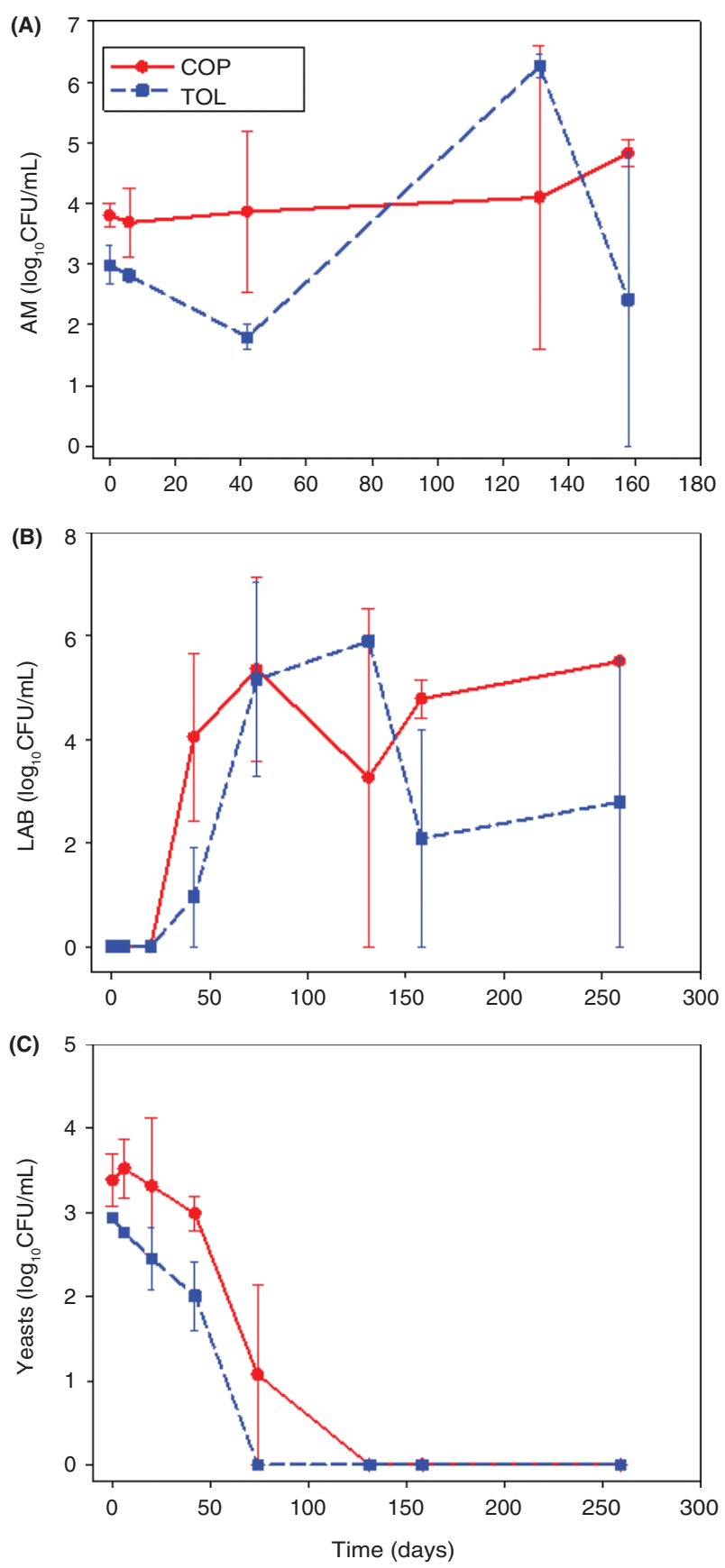

FIGURE 1. Changes in the AM, LAB and yeast populations in brine over time during shelf-life, according to industry (COP or TOL) (average $\pm \mathrm{SD} ; \mathrm{n}=2$ at each sampling point). 
(A)

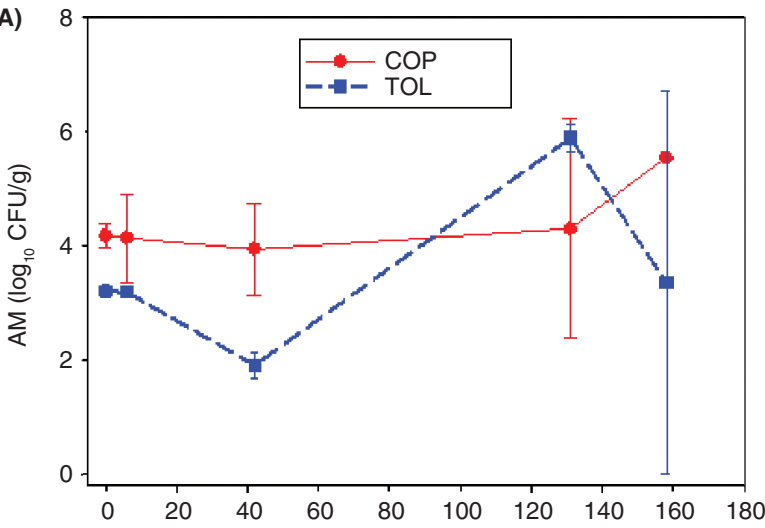

(B)

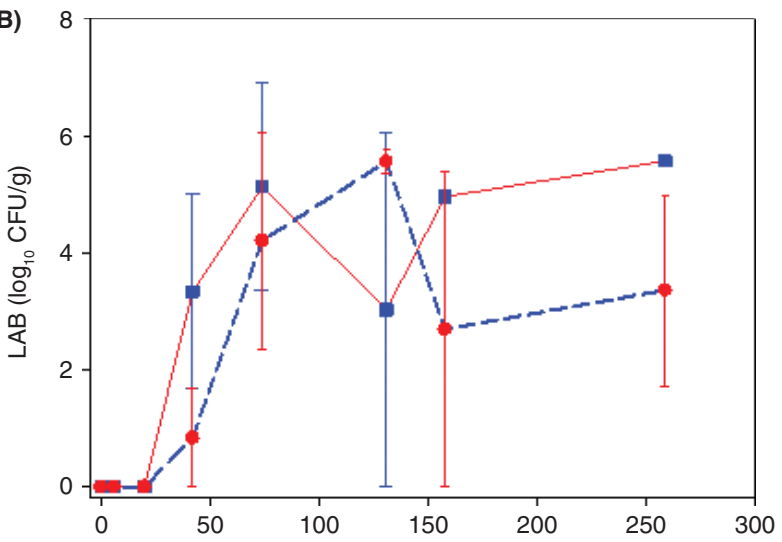

(C)

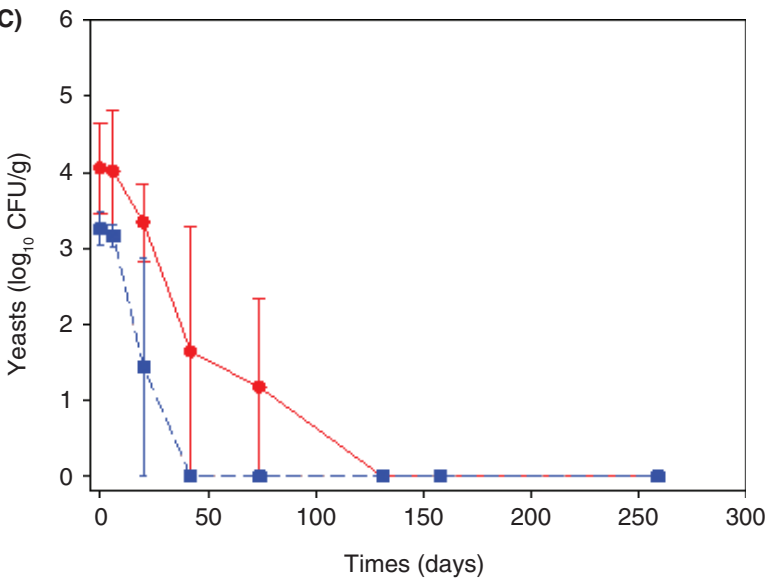

Figure 2. Changes in the AM, LAB and yeasts populations in olives over time during shelf-life, according to industry (COP or TOL) (average $\pm \mathrm{SD}, \mathrm{n}=2$ at each sampling point).

average counts in brine or olives from TOL were also lower (but not significantly different) than those from COP. As a result, yeasts in packages from TOL also fell below the detection limit earlier than in COP. The long permanence of yeasts in brines or olives, despite the use of preservatives, was not expected and may represent a spoilage risk during the first days of shelf-life if their metabolisms were not conveniently reduced.

\subsection{Changes in the physicochemical parameters of brine during shelf-life}

The changes in the LAB population were reflected on the evolution of $\mathrm{pH}$ and titratable acidity. Overall, the change in $\mathrm{pH}$ was moderate and moved from 4.654.75 down to $\sim 4.1$ (Figure 3, panel A). The pH trend (regardless of industry) was due to the simultaneous increase in titratable acidity, produced by the LAB during the first 140 days, which reached a maximum concentration of $\sim 0.6 \mathrm{~g} / \mathrm{L}$. The further decrease in $\mathrm{pH}$ might have been caused by the formed acid diffusion into the flesh when its production ceased. The hypothesis is also supported by the absence of any further change in acidity after reaching the equilibrium (Figure 3, panel $\mathrm{B}$ ). The combined acidity, in general, showed a slightly increasing trend, possibly caused by the lactic acid produced (Figure 3, panel C). On the contrary, the salt content, after a fist salt leakage from the fruits into the brine, was kept constant at approximately $45 \mathrm{~g} / \mathrm{Lin} \mathrm{COP}$ and $60 \mathrm{~g} / \mathrm{Lin}$ TOL, with remarkable differences between the two industries (Figure 3, panel D).

As expected, the primary metabolite formed during packaging was lactic acid (Fig.4), which was produced in variable rates (considerable variability between the packages during this period) and particularly during the final days of shelf-life. However, this lactic acid increment was not reflected as titratable acidity. The lack of correlation might have been caused by the probable incorporation of at least part of the lactic acid formed as combined acidity, which also increased slightly (Figure 3, panel C). However, in the Aloreña de Málaga, olive packages also contain other acids in addition to ethanol. In this case, the initial citric acid added at packaging progressively decreased, acetic acid showed a slight increase, which was likely due to the presence of heterofermentative LAB strains; while the ethanol concentration remained quite stable, indicating that the yeasts, although present, had a limited activity (Figure 4).

The amount of total sugar at the beginning of packaging was not abundant (1-2 g/L), and glucose was the main component in both TOL (highest concentration) and COP (Figure5). Only in the brines of COP total sugars were utterly exhausted at the end of the shelf-life (mainly because of the use of glucose and mannitol). In the packaging from the TOL industry, apparently only mannitol was consumed during packaging.

\subsection{Changes in the physicochemical parameters of olive fruits during shelf life}

The most affected characteristic during packaging was texture. Its instrumental value decreased 
(A)

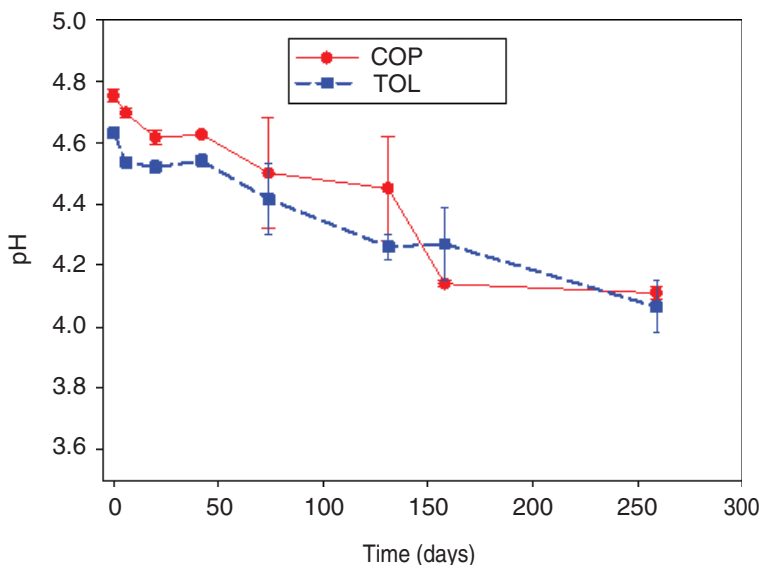

(C)

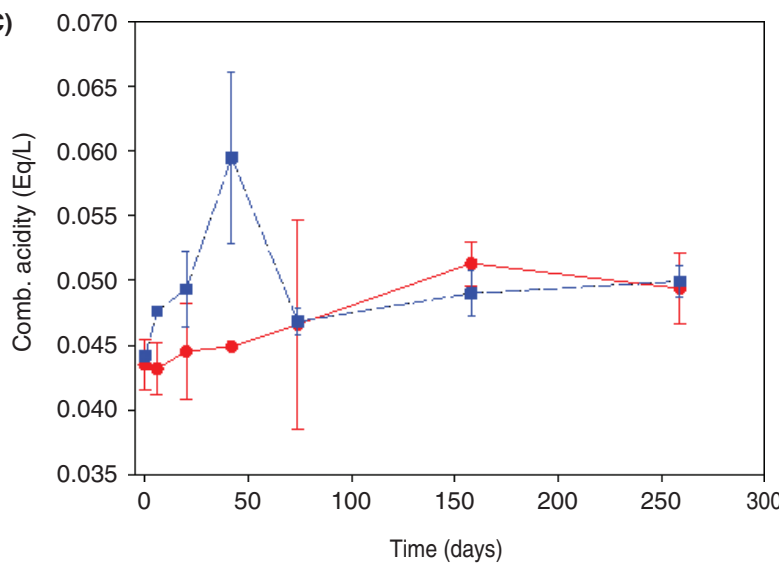

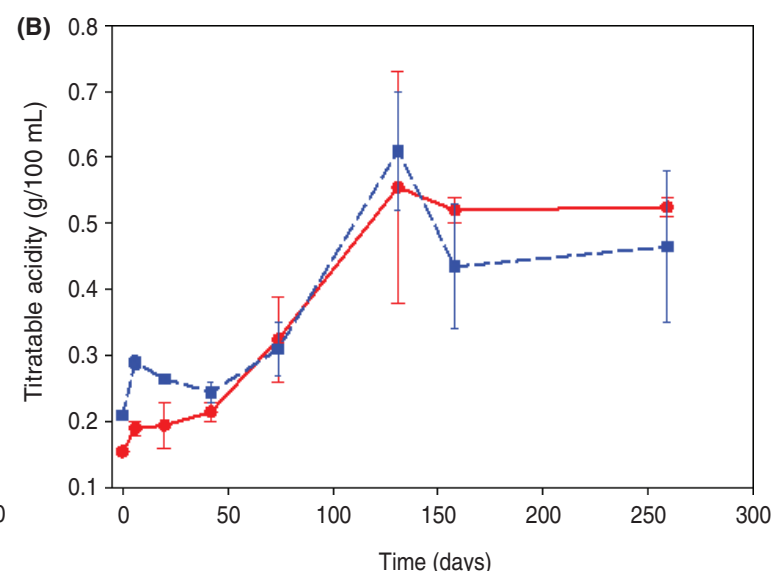

(D)

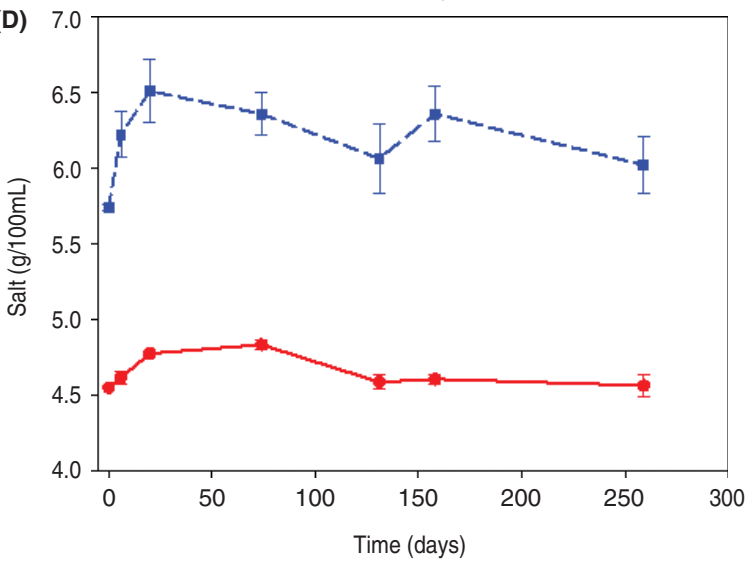

FIGURE 3. Changes in $\mathrm{pH}$, titratable acidity, combined acidity and salt content over time during shelf-life, according to industry (COP or TOL) (average $\pm S D, n=2$ at each sampling point).

from 7 to about $3.5 \mathrm{kN} / 100 \mathrm{~g}$ pitted olives at the end of study (Figure 6, panel A). According to Figure 5, the olives from both industries had similar textures and were degraded at the same rate.

With regard to fruit color (Figure 6, panels B and $\mathrm{C}$ ), the $L^{*}$ (luminance) values from TOL olives were lower than those from COP, although they followed similar trends over time. The changes may be summarized as a marked initial increase, possibly due to the impact of the low $\mathrm{pH}$ and high acidity of the fresh brine used at packaging, followed by a slight non-significant decreasing tendency. However, the $a^{*}$ values showed similar changes regardless of the industry, with the $a^{*}$ value increase being linked to LAB growth (from the $40^{\text {th }}$ day onward), with the subsequent production of titratable acidity, $\mathrm{pH}$ decrease and loss in the fruit's green appearance.

\subsection{Evaluation of fruits and packages}

At selected intervals, the samples were offered to the consumers for the evaluation of packages and fruits. The results (Tables1 and 2) were then subjected to nested (time within the type of industry)
ANOVA analysis (Table 3). The p-values for the overall model indicated that the following attributes were not significant at $p>0.05$ : brine turbidity, brine leakage, overall defects of fruits, and overall acceptability of fruits. In other words, the average values given to the containers (first two parameters) and fruits (last two) by the panellists were similar regardless of the industry and the sampling period and, consequently, did not significantly change throughout the shelf-life.

In addition, industry was not significant for any of the attributes related to the container appearance; although swelling, brine browning, and overall acceptability showed significant changes over time. After removing the variable industry, the model for these containers' attributes led to correct predictions (Figure 7). Swelling had a slight non-significant decrease during the first days of the shelf-life, with a progressive increase after the $74^{\text {th }}$ day (Figure $7 \mathrm{~A}$ ). On the contrary, brine browning always showed an increasing trend, which was more evident after the $74^{\text {th }}$ day and, notably, on the $133^{\text {rd }}$ day, with scores which were significantly different from those of the 0-42-day shelf-life containers (Figure 7B). Finally, overall acceptability always showed a decreasing 

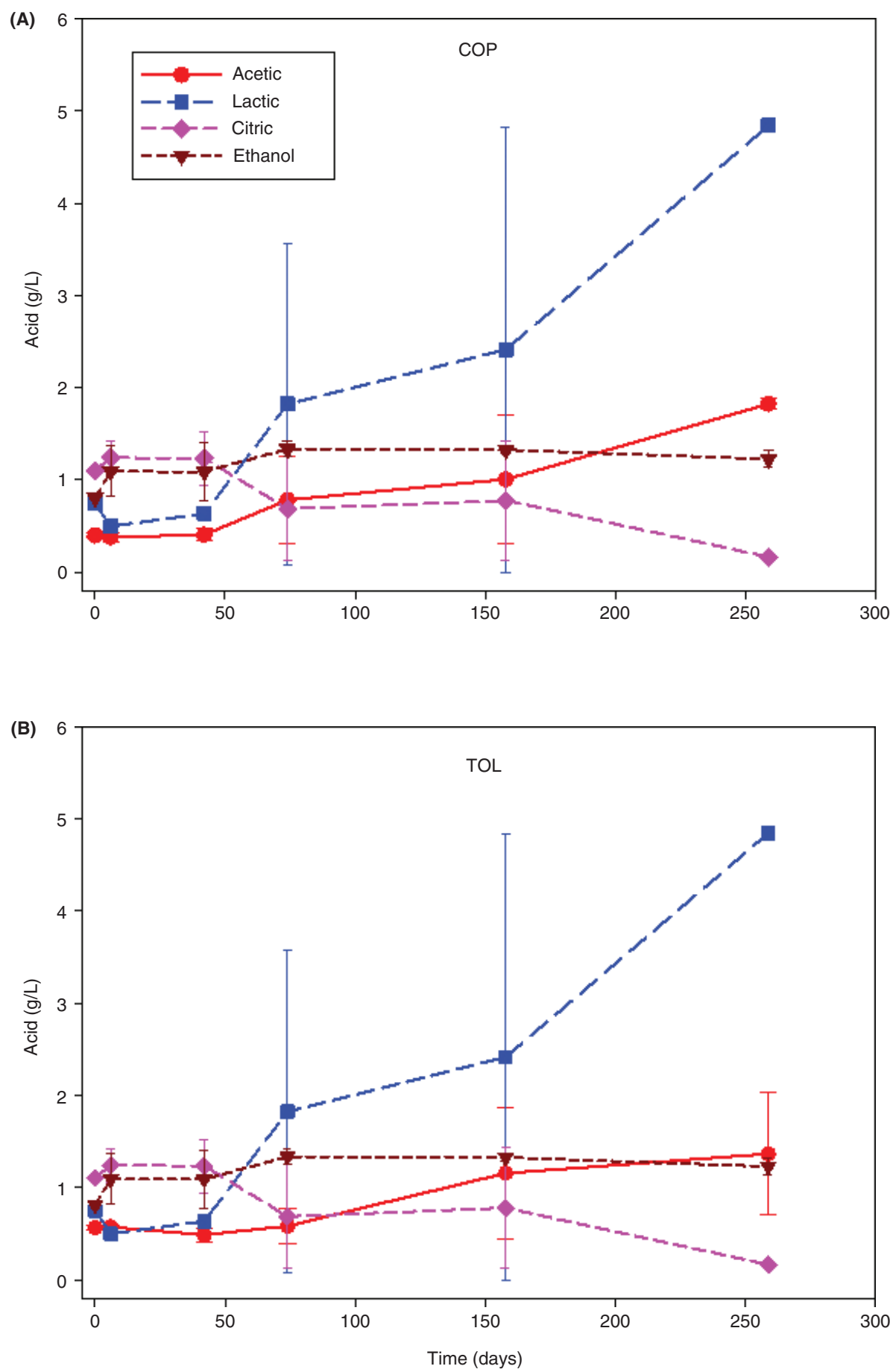

FIGURE 4. Changes in the lactic acid, acetic acid, citric acid and ethanol over time during shelf-life, according to industry (COP or TOL) (average $\pm \mathrm{SD}, \mathrm{n}=2$ at each sampling point).

trend, which was more rapid after the $74^{\text {th }}$ day of shelf-life (Figure 7C).

In the case of fruits, within the significant models, the industry did not have significant $(p>0.05)$ effects on browning, bruises, bitter, or crunchiness (Table 3) but all of them depended on time. The scores for fruit browning and bruises had abnormally high initial scores, due to a possible confusion on the initial evaluation by a panellist, which was later corrected since the following scores were lower and relatively similar over time. Thus, in practice, these attributes may be considered stable during 

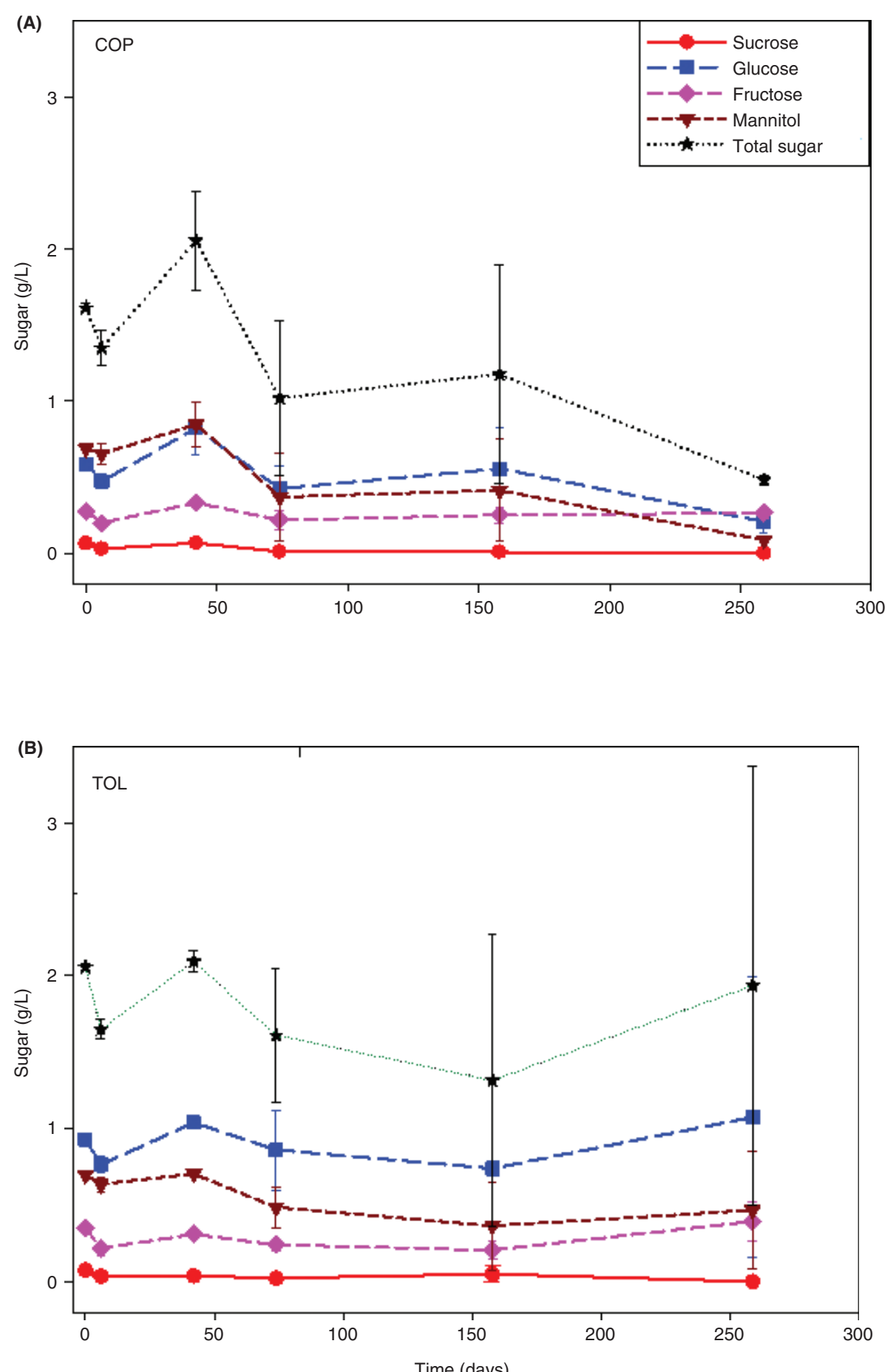

Figure 5. Changes in the total sugars, sucrose, glucose, fructose, and mannitol over time during shelf-life, according to industry (COP or TOL) (average $\pm \mathrm{SD}, \mathrm{n}=2$ at each sampling point).

the shelf-life period studied (Figures 7, D and E). Concerning bitterness, there was possibly an initial diffusion, due to its water solubility, followed by a certain re-equilibrium and a final decrease probably related to the hydrolysis of oleuropein. (Figure 7f). Crunchiness (Figure 7G) and hardness (Figure 8D) always increased significantly after packaging. The only attribute which depended on the industry was salty (Table 3 ), because of the different levels habitually used by them, as commented above; the scores for the olives from TOL were always higher than those from COP (Figure 7h).

The models of only two attributes (acidity, and hardness) depended on the two explanatory 

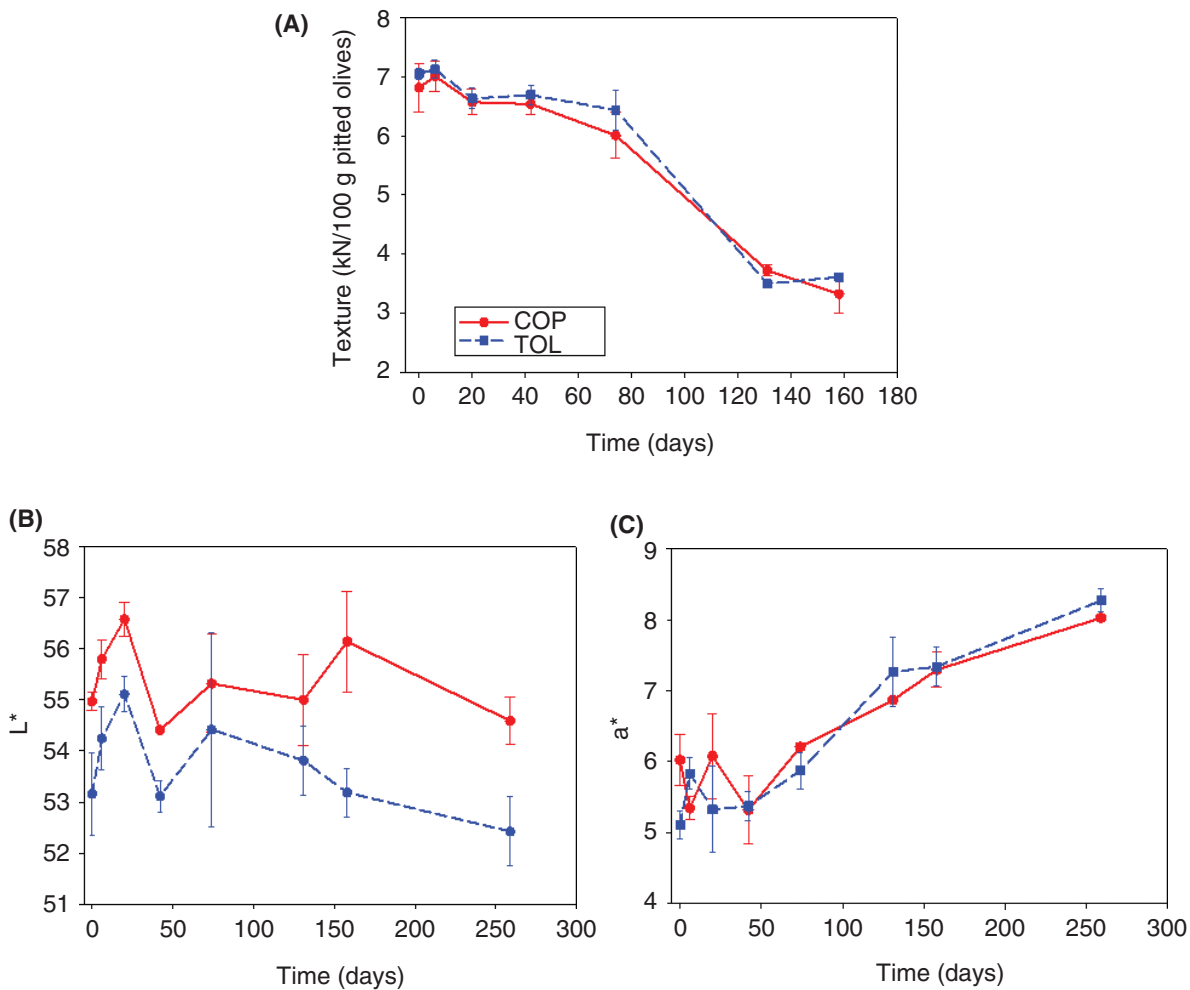

FIGURE 6. Changes in the texture, CIE L* and a* color parameters over time during shelf-life, according to industry (COP or TOL) (average $\pm S D, n=2$ at each sampling point).

TABLE 1. Scores received for the different attributes of packages and olives from the COP industry as well as their proportion of acceptance over shelf-life.

\begin{tabular}{|c|c|c|c|c|c|c|}
\hline \multicolumn{7}{|c|}{ Packaging time } \\
\hline & (0 days) & (6 days) & (20 days) & (42 days) & (74 days) & (131 days) \\
\hline \multicolumn{7}{|l|}{ Package container } \\
\hline Swelling & $1.25(0.35)$ & $0.66(0.20)$ & $0.91(0.24)$ & $0.62(0.16)$ & $1.21(0.36)$ & $1.80(0.48)$ \\
\hline Brine browning & $2.53(0.34)$ & $2.50(0.31)$ & $2.59(0.34)$ & $2.53(0.36)$ & $3.52(0.45)$ & $3.98(0.40)$ \\
\hline Brine turbidity & $3.48(0.39)$ & $2.91(0.37)$ & $2.84(0.39)$ & $3.42(0.40)$ & $3.94(0.41)$ & $4.19(0.44)$ \\
\hline Brine leakage & $1.28(0.41)$ & $0.53(0.15)$ & $0.68(0.22)$ & $0.33(0.05)$ & $1.58(0.48)$ & $1.15(0.40)$ \\
\hline Acceptability & $8.11(0.27)$ & $7.80(0.40)$ & $7.82(0.35)$ & $8.18(0.32)$ & $6.88(0.51)$ & $6.46(0.47)$ \\
\hline Buying pre-disposition (\%) & $97 \%$ & $94 \%$ & $97 \%$ & $94 \%$ & $84 \%$ & $81 \%$ \\
\hline \multicolumn{7}{|l|}{ Fruits } \\
\hline Browning & $6.37(0.32)$ & $2.42(0.33)$ & $1.97(0.28)$ & $2.06(0.30)$ & $2.85(0.36)$ & $2.63(0.52)$ \\
\hline Bruises & $6.77(0.27)$ & $2.11(0.32)$ & $2.03(0.34)$ & $1.99(0.32)$ & $1.87(0.29)$ & $2.24(0.44)$ \\
\hline Acidity & $3.65(0.37)$ & $2.89(0.35)$ & $2.53(0.32)$ & $2.55(0.29)$ & $3.31(0.30)$ & $2.82(0.55)$ \\
\hline Salty & $4.08(0.35)$ & $4.33(0.41)$ & $3.31(0.36)$ & $3.35(0.33)$ & $4.25(0.36)$ & $3.97(0.78)$ \\
\hline Bitter & $5.04(0.37)$ & $3.88(0.37)$ & $3.89(0.36)$ & $4.07(0.39)$ & $4.33(0.40)$ & $3.07(0.60)$ \\
\hline Hardness & $2.32(0.31)$ & $5.11(0.35)$ & $5.25(0.39)$ & $5.54(0.37)$ & $5.51(0.33)$ & $4.60(0.90)$ \\
\hline Crunchiness & $1.79(0.32)$ & $6.39(0.35)$ & $5.66(0.33)$ & $6.05(0.35)$ & $5.64(0.39)$ & $5.10(0.99)$ \\
\hline Defects & $1.89(0.30)$ & $1.52(0.34)$ & $1.92(0.40)$ & $2.18(0.42)$ & $2.18(0.44)$ & $2.41(0.47)$ \\
\hline Acceptability & $5.72(0.44)$ & $7.14(0.88)$ & $5.72(0.42)$ & $5.38(0.40)$ & $5.18(0.35)$ & $5.40(1.05)$ \\
\hline Buying pre-disposition (\%) & $66 \%$ & $74 \%$ & $77 \%$ & $64 \%$ & $72 \%$ & $69 \%$ \\
\hline
\end{tabular}

Note: Values are average $( \pm \mathrm{SD}) ; \mathrm{n}=35$ 
TABLE 2. Scores received for the different packages and olives from the TOL industry as well as their proportion of acceptance over shelf-life.

\begin{tabular}{|c|c|c|c|c|c|c|}
\hline \multicolumn{7}{|c|}{ Packaging time } \\
\hline & (0 days) & (6 days) & (20 days) & (42 days) & (74 days) & (131 days) \\
\hline \multicolumn{7}{|l|}{ Package } \\
\hline Swelling & $1.29(0.37)$ & $0.81(0.21)$ & $0.90(0.23)$ & $0.88(0.26)$ & $0.99(0.23)$ & $1.53(0.39)$ \\
\hline Brine browning & $2.89(0.36)$ & $2.96(0.33)$ & $3.34(0.35)$ & $3.21(0.42)$ & $3.26(0.40)$ & $4.22(0.52)$ \\
\hline Brine turbidity & $3.04(0.40)$ & $2.71(0.38)$ & $4.46(0.36)$ & $3.30(0.38)$ & $2.84(0.33)$ & $3.77(0.42)$ \\
\hline Brine leakage & $1.93(0.53)$ & $0.54(0.14)$ & $0.71(0.24)$ & $0.35(0.06)$ & $0.95(0.34)$ & $2.48(0.62)$ \\
\hline Acceptability & $7.85(0.35)$ & $7.70(0.42)$ & $7.10(0.42)$ & $7.89(0.40)$ & $7.06(0.49)$ & $6.05(0.49)$ \\
\hline Buying pre-disposition (\%) & $94 \%$ & $97 \%$ & $94 \%$ & $94 \%$ & $87 \%$ & $77 \%$ \\
\hline \multicolumn{7}{|l|}{ Fruits } \\
\hline Browning & $6.28(0.33)$ & $2.26(0.30)$ & $2.68(0.33)$ & $2.10(0.30)$ & $2.63(0.29)$ & $3.06(0.36)$ \\
\hline Bruises & $6.41(0.33)$ & $2.18(0.28)$ & $2.31(0.30)$ & $2.02(0.32)$ & $2.26(0.34)$ & $2.28(0.33)$ \\
\hline Acidity & $3.83(0.37)$ & $3.58(0.40)$ & $3.11(0.32)$ & $2.95(0.33)$ & $3.60(0.35)$ & $3.64(0.44)$ \\
\hline Salty & $5.19(0.44)$ & $4.82(0.41)$ & $4.61(0.32)$ & $5.04(0.36)$ & $5.76(0.42)$ & $5.10(0.43)$ \\
\hline Bitter & $5.36(0.34)$ & $4.51(0.45)$ & $3.67(0.35)$ & $4.05(0.36)$ & $5.23(0.39)$ & $3.23(0.42)$ \\
\hline Hardness & $3.10(0.35)$ & $5.40(0.37)$ & $5.21(0.35)$ & $5.65(0.40)$ & $5.78(0.35)$ & $5.37(0.44)$ \\
\hline Crunchiness & $2.60(0.40)$ & $5.98(0.40)$ & $5.36(0.38)$ & $8.74(2.62)$ & $6.12(0.37)$ & $6.02(0.39)$ \\
\hline Defects & $3.15(0.50)$ & $2.12(0.48)$ & $2.12(0.44)$ & $1.94(0.40)$ & $2.53(0.52)$ & $2.49(0.44)$ \\
\hline Acceptability & $5.12(0.40)$ & $5.92(0.42)$ & $5.65(0.37)$ & $5.67(0.38)$ & $4.32(0.34)$ & $5.81(0.40)$ \\
\hline Buying pre-disposition (\%) & $53 \%$ & $67 \%$ & $76 \%$ & $71 \%$ & $42 \%$ & $76 \%$ \\
\hline
\end{tabular}

Note: Values are average $( \pm \mathrm{SD}) ; \mathrm{n}=35$

variables of the ANOVA (industry and packaging time) (Table 3 and Figure 8). The olives from TOL had higher scores than those from COP for both parameters. The acidic scores showed an initial descending trend followed by an increase during the last days of shelf-life while hardness had an evolution similar to crunchiness (Figure 8).

The predisposition of the consumer (proportion who would buy the products or not), based on either the external appearance of the container or the sensory characteristics of the fruits, was arranged in a table similar to those used in the parametric survival curve. The Weibull model was fit, and their parameters and quartiles obtained. The table of quartiles allows for an estimation of the shelf-life according to the assumed proportions of dissatisfied consumers. Based on packages the model estimated a median of 153 days for the COP industry; that is, it should be expected that after 153 days, $50 \%$ of the consumers will be satisfied with the quality of the product. However, if one wishes to reduce the rejection risk to the first quartile $(25 \%)$, the shelf-life of the product should be reduced to only 39 days. On the contrary, after 252 (days) ( $3^{\text {rd }}$ quartile) only $25 \%$ of consumers will buy the product. The same study estimated a shorter shelf-life for TOL than for COP, which was 30,149 and 527 days for the $1^{\text {rst }}$ quartile, median, and $3^{\text {rd }}$ quartile, respectively. In any case, no model was able to be fit in the case of pre-disposition to buy based on the evaluation of fruits.
A multivariate study of the sensory data (Figure 9) showed that the fresh packaged olives, regardless of the industry, received similar and particular scores. They were characterized by high values for bitter, bruises and olive browning, although the association of the two last ones should not be real since bruises were produced before packaging. Also, fruits after the $7^{\text {th }}, 40^{\text {th }}$, and mainly the $133^{\text {rd }}$ packaging days were progressively different from the original ones and were associated with brine browning and turbidity. In general, the olives received the greatest acceptance at intermediate packaging days (6 to 42), regardless of the origin. Their positions were linked to low scores for swelling, pack leakage, defects, acidic, and salty and also, but to a lesser degree, to hardness, crunchiness, package acceptance and olive acceptance.

\section{DISCUSSION}

A survey carried out one decade ago on Aloreña de Málaga packaging showed that the leading cause of instability, due to swelling and brine leakage, were diverse. In the fresh packaging, the problem was caused by the carbon dioxide produced by the fruits' respiration. However, in the traditional presentations, the spoilage was caused by the gas formed by the natural microbiota, mainly yeasts, whose counts markedly increased during shelf-life (Arroyo-López et al., 2009). The microbial load on 


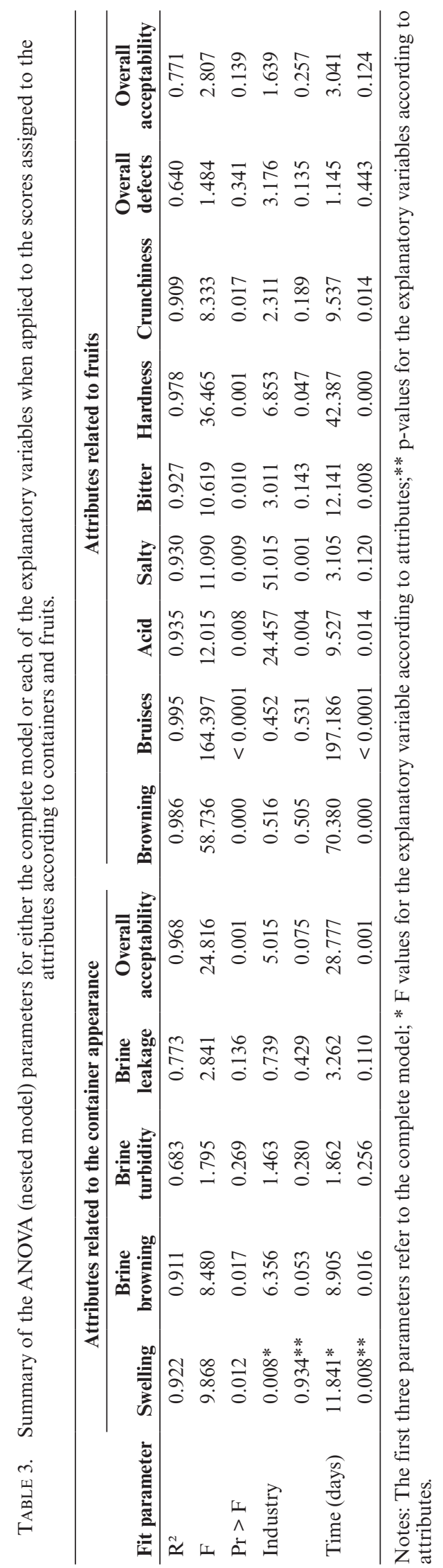



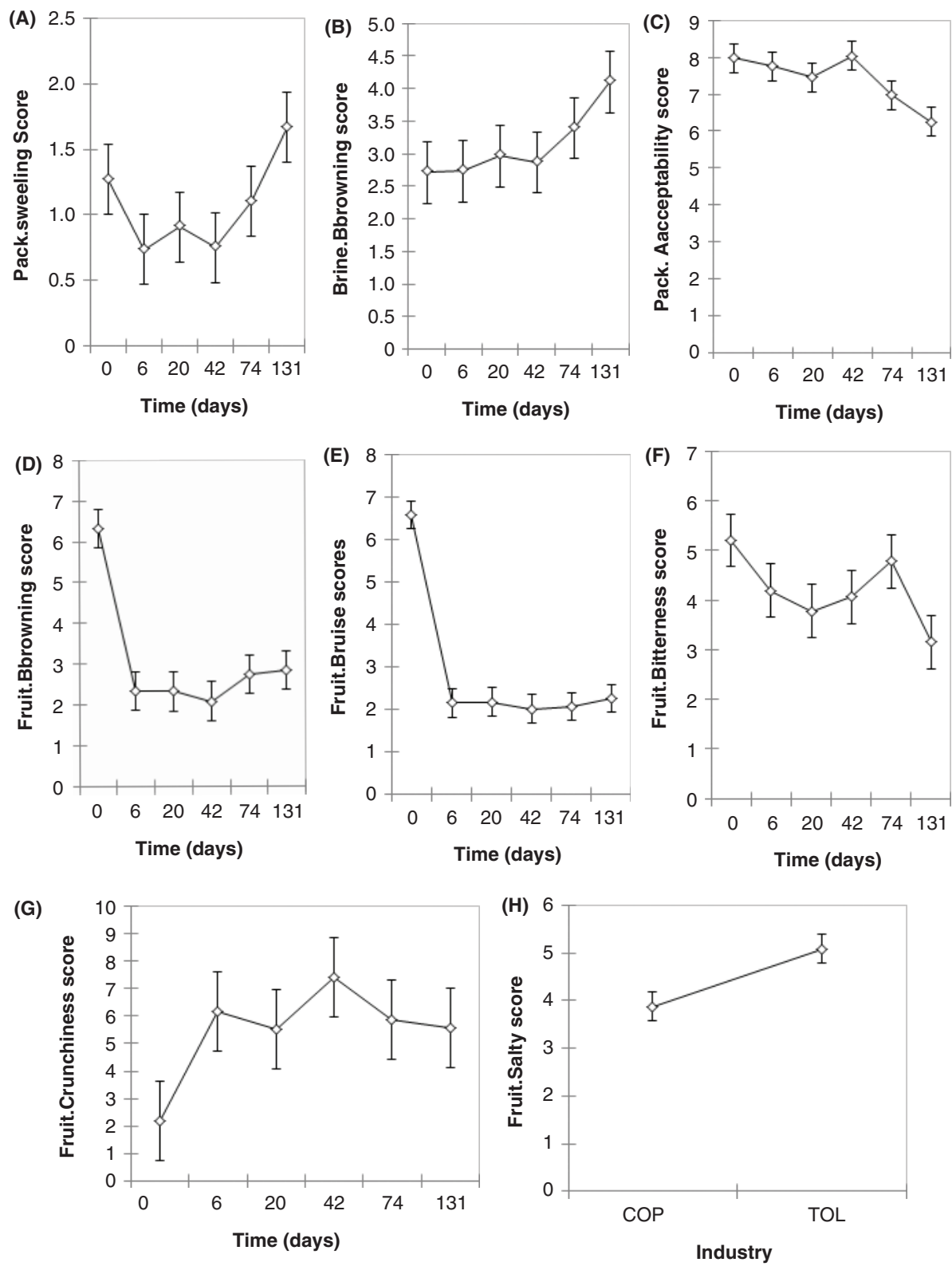

FIGURE 7. Predictions based on the nested (time within origin) ANOVA for significant model based on only one attribute (shelf-life periods or industry) (Values are LSM $( \pm C L)$; freedom degree for $S D=6$ or $=10, \mathrm{H})$.

the packaged olives was due to a carry-over effect, which caused a progressive accumulation of microorganisms from the previous storage/fermentation, the packaging operations, and the natural ingredients added at packaging (Arroyo-López et al., 2009). The initial microbiota in Aloreña de Málaga olives may depend on the type of storage. Yeasts seemed to be the most predominant populations when the olives were stored in cold rooms (Saccharomyces cerevisiae and Candida cf. apicola); while LAB counts increased towards the end of the storage in plastic drums and large-scale vessels at ambient temperatures (Abriouelet al., 2011). Among the LAB, a total of 144 isolates from small, medium enterprises were characterized. They included lactobacilli (82\%), Leuconostoc (10\%), and pedioccocci (8\%) with Lactobacillus pentosus, Pediococcus parvulus, and Leuconostoc pseudomesenteroides being the only species identified (Abriouel et al., 2012). However, they were not clearly related and exhibited a considerable degree of genomic diversity for lactobacilli and Leuconostoc.

Diverse treatments have been applied to promote the retention of freshness and diminish the level 

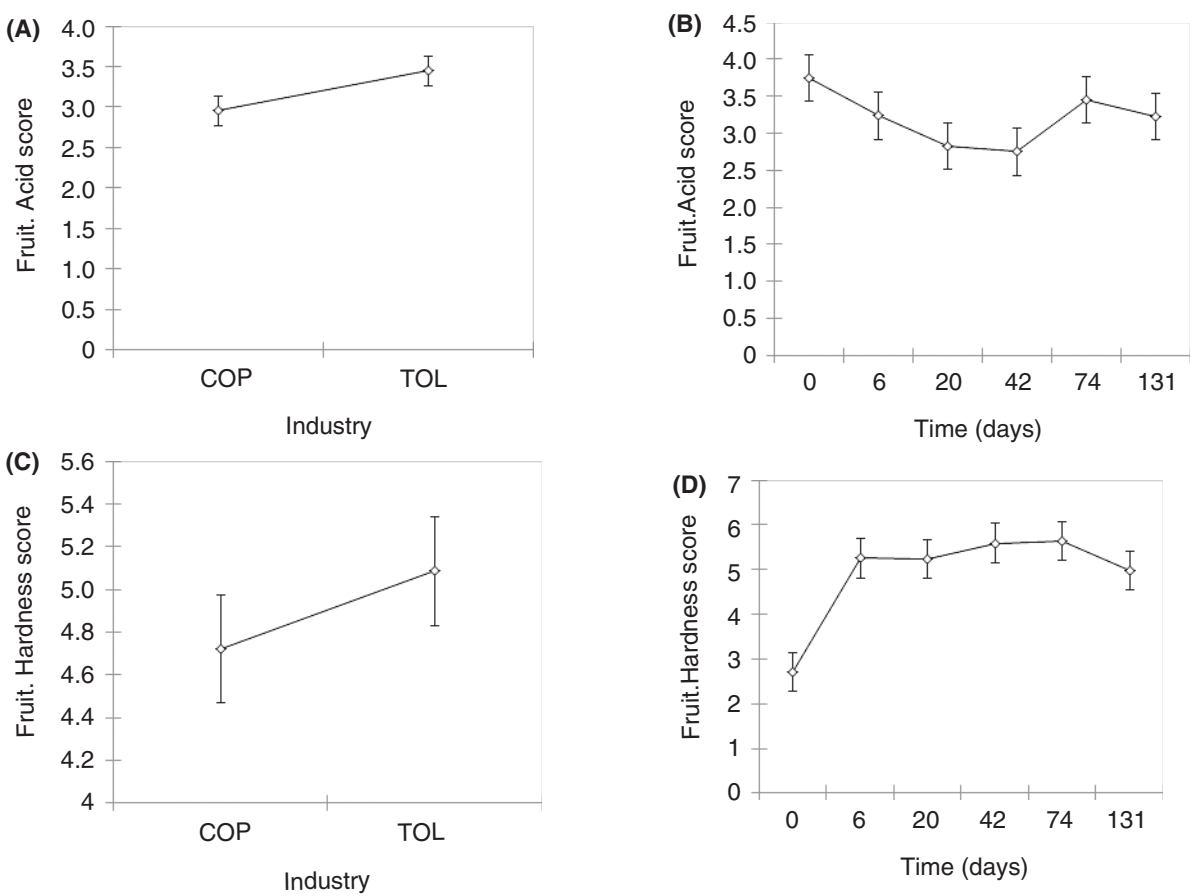

FIGURE 8. Predictions based on the nested (time within origin) ANOVA for acid and hardness as a function of the industry (COP or TOL) and shelf-life time (Values are LSM $( \pm C L)$; freedom degree for $\mathrm{SD}=10, \mathrm{~A}$ and $\mathrm{C}$ or $=10$, B and $\mathrm{D}$ ).

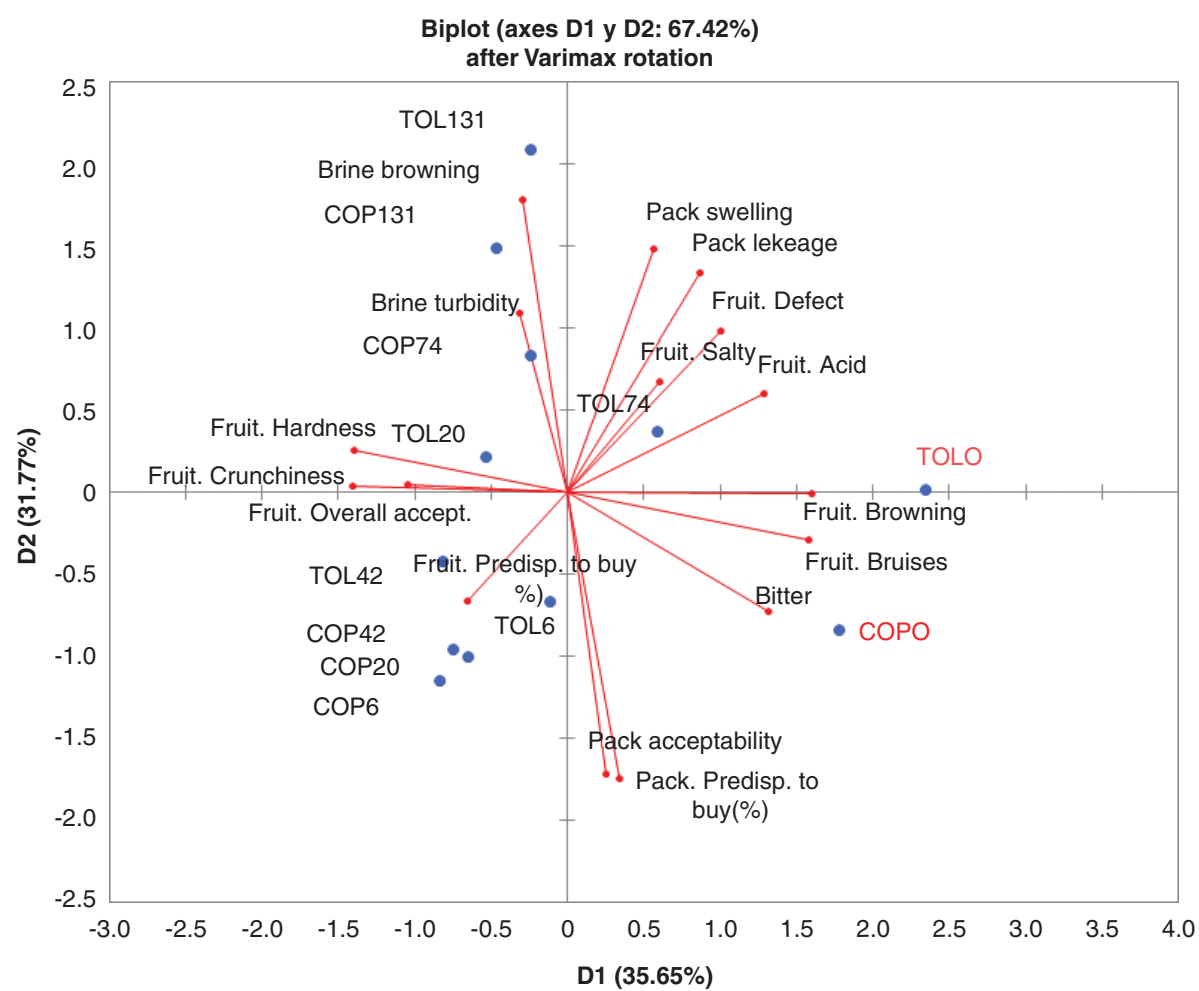

FIGURE 9. Relationships according to multivariate (bi-plot) analysis, among the scores of the attributes evaluated in containers and fruits, shelf-life periods, and industry (COP or TOL). 
of microorganisms during the storage/fermentation of Aloreña de Málaga fruits (Arroyo-López et al., 2008a). The use of ascorbic acid (up to $15 \mathrm{~g} / \mathrm{L}$ ) reduced the de-greening rate. On the contrary, the addition of sodium metabisulphite $(1.5 \mathrm{~g} / \mathrm{L})$ partially inhibited the LAB population at intermediate concentrations of ascorbic acid $(7.5 \mathrm{~g} / \mathrm{L})$ and the highest $\mathrm{NaCl}$ level $(70 \mathrm{~g} / \mathrm{L})$ but did not affect yeast growth. Therefore, a modified storage/fermentation using maximum levels of ascorbic acid and sodium metabisulphite could improve olive color and reduce the carry-over LAB population into packaged products.

The combined use of sorbate and benzoate is allowed in table olives (IOC, 2004) but their minimum inhibitory concentrations (MIC) or possible synergy has been scarcely studied. Arroyo-López et al., (2008b) were the first to investigate their specific effects on a cocktail of the main species of yeasts usually found in Aloreña de Málaga olives. At pH 4.0, the average level for this speciality, the MIC for sorbic and benzoic acids were 3.31 and 10.0 $\mathrm{mM}$, respectively. However, no synergy between them was found. The study was useful for fixing the appropriate level of preservatives, which at the current packaging conditions used in this work, not only prevented yeast growth but caused their disappearance, although not as fast as desirable. However, such conditions were not strong enough for preventing the rapid growth of LAB after a short lag phase during shelf-life. It was detected that the behaviors of LAB and yeasts, in brine or on fruits, were opposed, indicating a certain competitiveness between these groups of microorganisms. This similarity between the matrices could be due to the easy exchange of components between the brine and the cracked olives. Conversely, the high variability found in the microbial changes indicates that the packaging conditions do not promote a homogeneous behaviour but particular responses, depending on the package. Therefore, the preservation conditions used do not represent a robust procedure and call for reconsideration, including the history of olive processing.

From a safety point of view, the $\mathrm{pH}$ decrease and the formation of lactic acid (about $0.6 \mathrm{~g} / \mathrm{L}$ brine), as observed in this study, are interesting and help to improve the antifungal activity of the preservatives and, subsequently, the disappearance of yeasts.

However, these changes may also produce a progressive decrease in texture and the greenish appearance of the olives as demonstrated by Brenes et al., (1994), and Gallardo-Guerrero et al., (2013), respectively, with the changes related to the color being particularly important for Aloreña de Málaga olives. However, the fading of the green color should not be associated exclusively with the packaging shelf-life itself since the main changes in this attribute occurred during the first storage month, although its degradation continues at lower rates throughout the entire storage/fermentation and packaging periods (Gallardo-Guerrero et al., 2013). At the same time, there is an accumulation of the brown pigments derived not only from the polyphenol oxidation but from the degradation of chlorophylls as well. The increase observed in the $a^{*}$ values are then strongly negatively, or positively, correlated to the overall green, or brownish pigments, respectively (Gallardo-Guerrero et al., 2013).

The changes in the LAB population caused few problems with the appearance of the olives in this work, as deduced from the sensory evaluation throughout the shelf-life. However, an excessive $\mathrm{LAB}$ presence may represent a potential risk of spoilage like the one produced by the particular phenotype of $L$. pentosus, which caused alteration in the olive flesh (Romero-Gil et al., 2016). Subsequently, although not harmful for health and of reduced influence on organoleptic characteristics, LAB presence should also be controlled. The use of some antioxidant (e.g. erythorbic acid, usually added to Aloreña de Málaga at packaging), may promote microbial growth and firmness deterioration (Romero-Gil et al., 2016). Therefore, this work confirms new sources of instability in Aloreña de Málaga packaging and focuses the interest now on reducing $\mathrm{LAB}$ growth, although the objective is quite tricky because of the ability of this microbial group to use various olive compounds, such as mannitol, or even polyphenol glucosides as nutrient sources as observed in this work.

With regard to the sensory characteristics, the number of attributes evaluated was lower than those proposed by Galán-Soldevilla et al., (2013) but higher than those proposed by the IOC (2011). In fact, our evaluation sheet not only included those already present in the IOC Evaluation Sheet but a few additional ones. In general, the evaluation sheet proved to be adequate, although it led to sporadic abnormal scores at the first sampling times (browning or bruises), probably by an incorrect application to Aloreña de Málaga of similar quality criteria to green Spanish-style. However, apart from these, no abnormal attribute changes were observed during shelf-life. The lack of significance of the model for overall fruit acceptability means that, regardless of the other attributes, the fruits were similarly acceptable during the whole shelf-life period studied. This behavior is in agreement with the proportion of consumers who would buy the product, which remained substantially the same during the shelf-life, regardless of the production industry. The level of buying pre-disposition based on the container appearance was even higher, indicating that this criterion may not be in agreement with that of olive fruits when determining the product's shelf-life. 
Even in case of ANOVA significant models, the fruits from both industries received statistically similar scores in several attributes (swelling, browning, overall container acceptability, browning, bruises, bitter, and crunchiness), although most of them showed significant changes during shelf-life. The initial slow decrease in bitter scores was due to the diffusion of phenols into the brine while the sharp decrease can be related to their hydrolysis (mainly oleuropein) by some of the LAB strains present at the end of the shelf-life. The increase in crunchiness and hardness after packaging may be due to the absorption of $\mathrm{Ca}^{++}$(from the water or concentrated brine used for the cover solution) by the olive flesh. Salty was the only attribute which depended exclusively on industry. The differences found should be attributed to the different salt concentration during the previous storage/fermentation phase since both companies use similar salt concentrations in the brines used for packaging.

Only the scores of two attributes (acidic and hardness) depended on the previous storage/fermentation and packaging conditions simultaneously. The different levels of acid between the two industries are due to the different acidification level in their respective storage/fermentation solutions. The first changes in acid may be due to its initial equilibrium of acid between fruits (which apparently had higher contents than those required after packaging), but the next increment in acidic taste should be caused by the acid produced by the LAB. The initial increase in hardness was possible due to absorption by the flesh of the $\mathrm{Ca}^{++}$from the water or the concentrated salt solution used to prepare the cover packaging brine; however, once the absorption is finished, the stability of this attribute may be due to the absence of additional sources of $\mathrm{Ca}^{++}$. The final decrease in hardness at the end of shelflife may be linked to the effect of the lactic acid produced and the subsequent $\mathrm{pH}$ decrease (Brenes et al., 1994).

In general, the proportion of consumers showing a pre-disposition to buying the product was above the median, except at 74 days for olives from TOL. Since the estimations of shelf-life could be obtained only from answers based on package appearance, no estimations of the shelf-life of the packaged olives can be deduced. Therefore, the first impact of the product on consumers is related to the packages' appearance (absence of swelling or leakage) which, in turn, is the result of a low yeast activity; apparently, they, although present, had a limited metabolic activity and produced only a reduced level of $\mathrm{CO}_{2}$. Evidently, the current packaging conditions cause strong yeast inhibition but scarce control over LAB growth. Consequently, the current shelf-life of Aloreña de Málaga table olives is longer than that observed in previous surveys (Arroyo-López et al., 2009) but the pre-disposition of the consumer to use them decreases progressively after approximately 50 days of putting them on the market. Furthermore, since the consumers who will buy the product, based on fruit quality, decreased after 149-153-day packaging period, above 150 days only $50 \%$ consumer will choose them. This evolution, although, less sensitive to health risks, may also lead to economic losses, product deterioration and, in the end, consumer and dealer distrust in the product (RomeroGil et al., 2016). The shelf-life of these olives contrasts with those observed for green table olives which were always classified as "extra" according to the methodology used by the International Olive Council (IOC, 2011). No significant changes in the other sensory attributes were observed during the 3 years of shelf life expected for the product. An accelerated shelf-life test performed with ripe olives García García et al., (2008) showed that the most influential variable in their shelf-life was temperature, which could ruin the product rapidly when storing it above $30{ }^{\circ} \mathrm{C}$. However, a study performed at room temperature confirmed a slight progressive decline with time, following first-order kinetics. No changes were observed in most attributes over the three years the assay lasted and, subsequently, the samples were classified as "extra", except for the plain Gordal presentation which was evaluated as "first, choice" or "select". Therefore, the most commonly consumed table olive styles had markedly higher shelf-lives than Aloreña de Málaga.

\section{CONCLUSIONS}

This survey has demonstrated that the current packaging conditions of Aloreña de Málaga table olives, despite their apparent assumed stability, cause important changes in diverse attributes of the product. In fact, a marked microbial activity mainly related to the presence and growth of LAB during the entire shelf-life was detected. Such activity caused changes in $\mathrm{pH}$, titratable acidity, texture and the greenish appearance during shelflife but hardly influenced the external appearance of the packages and their sensory characteristics for 42 days. Later, a progressive decrease in the appreciation of the products by the consumer was observed although they had a limited impact on product refusal. Furthermore, after 134 days of shelf-life, the products still received consumer support above the median, and, on the $144^{\text {th }}$ day, they still showed an approximate $50 \%$ buying predisposition. However, the results pointed out the convenience of modifying the current packaging conditions so the LAB activity should also be controlled not only throughout the current shelf-life but for more extended periods to allow further market expansion. 


\section{ACKNOWLEDGEMENTS}

The research leading to these results has received funding from Junta de Andalucía Government through the PrediAlo project (AGR-7755: www. predialo.science.com.es) and FEDER European funds. VRG would like to thank ceiA3, Spanish Government, Bank of Santander, IG-CSIC and 'Aloreña de Málaga' Olive Manufacturing Association for her pre-doctoral fellowship.

\section{REFERENCES}

Abriouel H, Benomar N, Lucas R, Gálvez A. 2011. Cultureindependent study of the diversity of microbial populations in brines during fermentation of naturally-fermented Aloreña green table olives. Int. J. Food Microbiol. 144, 487496. https://doi.org/10.1016/j.ijfoodmicro.2010.11.006

Abriouel H, Benomar N, Cobo A, Caballero N, Fernández Fuentes MÁ, Pérez-Pulido R, Gálvez A. 2012. Characterization of lactic acid bacteria from naturally-fermented Manzanilla Aloreña green table olives. Food Microbiol. 32, 308-316. https://doi.org/10.1016/j.fm.2012.07.006

Arroyo-López FN, Bautista-Gallego J, Durán-Quintana MC, Garrido-Fernández A. 2008a. Effects of ascorbic acid, sodium metabisulfite and sodium chloride on freshness retention and microbial growth during the storage of Manzanilla-Aloreña cracked table olives. LWT - Food Sci. Technol. 41, 551-560. https://doi.org/10.1016/j.lwt.2007.05.016

Arroyo-López FN, Bautista-Gallego J, Durán-Quintana MC, Garrido-Fernández A. 2008b. Modelling the inhibition of sorbic and benzoic acids on a native yeast cocktail from table olives. Food Microbiol. 25, 566-574. https://doi. org/10.1016/j.fm.2008.02.007

Arroyo-López FN, Bautista-Gallego J, Segovia-Bravo KA, García-García P, Durán-Quintana MC, Romero C, Rodríguez-Gómez F, Garrido-Fernández A. 2009. Instability profile of fresh packed "seasoned" ManzanillaAloreña table olives. LWT Food Sci. Technol. 42, 16291639. https://doi.org/10.1016/j.lwt.2009.06.004

Brenes M, García P, Garrido A. 1994. Influence of salts and $\mathrm{pH}$ on the firmness of olives in acid conditions. J. Food Oual. 17, 335-346. https://doi.org/10.1111/j.1745-4557.1994.tb00155.x
Columela LJM. 42. De Re Rustica. Vol. II, Book XII. Nestlé A.E.P.A. Santander. Spain, pp. 209-213 (1979).

Galán-Soldevilla H, Pérez-Cacho PR, Campuzano JH. 2013. Determination of the characteristic sensory profiles of Aloreña table-olive. Grasas Aceites 64, 442-452. https://doi. org/10.3989/gya.132312

Gallardo-Guerrero L, Gandul-Rojas B, Moreno-Baquero J, López-López A, Bautista-Gallego J, Garrido-Fernández A. 2013. Pigment, physicochemical, and microbiological changes related to the freshness of cracked table olives. $J$. Agric. Food Chem. 61, 3737-3747.

García García P, López López A, Garrido Fernández A. 2008. Study of the shelf life of ripe olives using an accelerated test approach. J. Food Eng. 84, 569-575. https://doi. org/10.1016/j.jfoodeng.2007.06.023

García García P, Sánchez Gómez AH, Garrido Fernández A. 2014. Changes of physicochemical and sensory characteristics of packaged ripe table olives from Spanishcultivars. Int. J. Food Sci. Technol. 49, 895-903. https://doi. org/10.1111/ijfs. 12383

Garrido-Fernández A, Fernández Díez MJ, Adams RM. 1997. Table olives: Production and Processing. Chapman \& Hall, London, United Kingdom, pp. 67-109.

International Olive Council (IOC). 1987. Sensory analysis of olive oil standard glass for oil tasting. COI/T20/Doc $\mathrm{n}^{\circ} 5$, Junio 1987. Madrid (Spain).

International Olive Council (IOC). 2004. Trade standard applying to table olives. COI/OT/NC Nº, December 2004. Madrid (Spain).

International Olive Council (IOC). 2011. Method sensory analysis of table olives. COI/OT/MO No1/Rev.2, Noviembre 2011. Madrid (Spain).

Official Journal of the European Union (DOUE). 2012. Regulation $\mathrm{N}^{\circ} 1068 / 2012$. L318/3-L318/4

Romero-Gil V, Rodríguez-Gómez F, Garrido-Fernández A, García-García P, Arroyo-López FN. 2016. Lactobacillus pentosus is the dominant species in spoilt packaged Aloreña de Málaga table olives. LWT - Food Sci. Technol. 70, 252260. https://doi.org/10.1016/j.lwt.2016.02.058

Sánchez AH, de Castro A, Rejano L, Montaño A 2000. Comparative study on chemical changes in olive juice and brine during green olive fermentation. J. Agric. Food Chem. 48, 5976-5980. https://doi.org/10.1021/jf000563u

Sánchez Gómez AH, García García P, Garrido Fernández A. 2013. Spanish-style green table olives shelf-life. Int. J. Food Sci. Technol. 48, 1559-1568. https://doi.org/10.1111/ ijfs. 12124 